\title{
Degree of Beta-Blockade and Outcomes in Patients with Acute Coronary Syndrome
}

\author{
Sachin Kumar Amruthlal Jain ${ }^{1 *}$, Timothy R. Larsen $\mathrm{DO}^{2}$, Charlotte Wiemann², Patrick Alexander ${ }^{1}$, Michael Shaw ${ }^{3}$, Peter A McCullough ${ }^{4}$ and \\ Shukri David
}

${ }^{1}$ Division of Cardiology, Providence Heart Institute, Providence Hospital and Medical Centers, Southfield, Michigan, USA

${ }^{2}$ Division of Internal Medicine, Providence Hospital and Medical Centers, Southfield, Michigan, USA

${ }^{3}$ Department of Patient Care Research, St. John Providence Health System, Macomb, Michigan, USA

${ }^{4}$ Chief Academic and Scientific Officer, St. John Providence Health System, Providence Park Heart Institute, Novi, MI, USA

\begin{abstract}
Objective: We sought to determine if the outcome benefit of beta blockade in the ACS population is associated with baseline HR, discharge HR, or a reduction in HR.

Background: ACC guidelines recommend a resting HRgoal of 50 to $60 \mathrm{bpm}$ in ACS patients. This recommendation is not based on study outcomes, but rather on expert opinion. Evidence-based clinical trials investigating ideal target heart rate of beta blocker (BB) therapy in the ACS population are lacking.

Methods: A retrospective analysis was performed of all ACS patients who underwent coronary angiography (with or without percutaneous coronary intervention) at Providence Hospital from September 2006 to August 2011 excluding patients with any contraindication to BB therapy. Discharge HR was used as the predictor variable for outcomes in these patients.

Results: A total of 912 patients (403 ST elevation myocardial infarction MI (STEMI) and 509 Non STEMI patients were included. Discharge HR was divided into quintiles: quintile 1 (48 - $64 \mathrm{bpm}$ ), quintile 2 (65 - 70), quintile 3 (71 - 76), quintile $4(77-83)$ and quintile $5(84-119)$. There was a statistically significant difference seen between the quintile 1 composite endpoint and the other quintile endpoints. ( $p$ value $<0.05$ ) No differences were seen across quintiles in median TIMI risk index score at admission, systolic and diastolic blood pressure or beta-blocker dose at discharge. Patients in quintile 1 fared better overall with the observation of worse outcomes in patients with a discharge heart rate less than 55.
\end{abstract}

Conclusion: In those with ACS, particularly STEMI and NSTEMI, a lower discharge HR conferred a decreased composite endpoint at 24 months with the best outcomes seen at a resting HR between 55-65. Further studies are needed to investigate the clinical benefit of optimal HR reduction in this population beyond 2 years.

Keywords: Beta blockade; Resting heart rate; Acute coronary syndrome

\section{Background}

Cardiac ischemia can manifest across a disease spectrum including unstable angina (UA), non-ST elevation myocardial infarction (NSTEMI) and ST elevation myocardial infarction (STEMI). These unstable ischemic conditions are described clinically as Acute Coronary Syndrome (ACS). Typically, the ischemia associated with ACS is the result of atherosclerotic changes of the coronary arteries, which can eventually lead to acute or chronic vessel occlusion. Coronary artery disease is the leading cause of morbidity and mortality in the United States with ACS accounting for more than 1.6 million hospital admissions per year. The estimated economic burden of ACS is 150 billion dollars annually $[1,2]$.

The American College of Cardiology (ACC) and the American Heart Association (AHA) recommend timely identification and treatment of ACS. The 2007 ACC/AHA guidelines for management of acute NSTEMI recommend that oral beta-blocker therapy be initiated within 24 hours of presentation as a class I indication for patients without contraindications. The guidelines also recommend oral betablockers upon discharge for this patient population [3]. The 2010 ACC/ AHA guidelines for acute STEMI recommend the administration of oral beta-blockers in hemodynamically stable patients starting postMI day 2 onward. Guidelines also suggest that in this population betablocker therapy has its greatest benefit in the first three years and in patients with left ventricular systolic dysfunction (left ventricular EF of $40 \%$ or less). For patients without class I indications (hypertension, angina, and heart failure), therapy with beta-blockers is a class IIa or IIb recommendation. Further recommendations include anti-platelet medications, ACE Inhibitors, Statins, regular physical activity, blood pressure control, and smoking cessation.

Beta-blocker therapy is considered fundamental in the management of patients with ACS. This is based on data first established over 30 years ago which demonstrated a survival benefit in post-MI patients on beta-blocker therapy. Beta-blockers have been shown to reduce mortality in the acute phase of ACS as well as reduce the risk of sudden cardiac death and re-infarction [4]. Blocking of the beta-receptors causes a decrease in both heart rate and blood pressure, which leads

*Corresponding author: Sachin Kumar Amruthlal Jain, Providence Heart Institute, Providence Hospital and Medical Centers, 16001 West Nine Mile Road, Southfield, MI 48075, USA, Tel: (248) 961-1758; Fax: (248) 849-2075; E-mail: doctorsachin@gmail.com

Received February 17, 2014; Accepted March 21, 2014; Published March 28 2014

Citation: Jain SKA, Larsen TR, Wiemann $C$, Alexander $P$, Shaw $M$, et al. (2014) Degree of Beta-Blockade and Outcomes in Patients with Acute Coronary Syndrome. J Cardiovasc Dis Diagn 2: 150. doi:10.4172/2329-9517.1000150

Copyright: @ 2014 Jain SKA, et al. This is an open-access article distributed unde the terms of the Creative Commons Attribution License, which permits unrestricted use, distribution, and reproduction in any medium, provided the original author and source are credited. 
to decreased myocardial contractility, reduction in myocardial oxygen demand and decreased frequency of ventricular arrhythmias [5]. The slower heart rate allows for a prolonged diastolic phase, which in turn improves circulation through the coronary arteries. Reduction in adrenergic activity as well as catecholamine levels may also play a part in reducing oxygen demand and lend toward favorable redistribution of blood respectively. Beta-blockade has been shown to lower circulating catecholamine levels in rats with heart failure after myocardial infarction via a reduction in adrenal G-protein coupled receptor kinase-2 activity and subsequent decrease in adrenal epinephrine release [6].

Some studies suggest that tachycardia is a strong predictor of mortality in subjects with coronary artery disease. A heart rate (HR) between 80 and 85 beats per minute (bpm) has previously been considered a reasonable cut off between a normal to high rate [7]. A recent meta-regression analysis showed that in several randomized beta-blocker trials a statistically significant relationship was seen between HR reduction and log odds ratio for cardiac death $(\mathrm{P}=0.02$, meta-regression slope $=0.039)$, sudden death $(\mathrm{P}<0.01)$ and non-fatal MI recurrence $(\mathrm{P}<0.01)$. The analysis demonstrated that for every 10 beat per minute reduction in HR there was a $30 \%$ reduction in the relative risk of cardiac death [8]. The study also stated that the absence of residual heterogeneity suggested reduction in resting HR was likely the major determinant of the clinical benefit demonstrated. Additionally, treating heart rate has been shown to correlate better with cardiovascular outcomes than reaching a target dose of beta-blockers in patients with systemic hypertension and systolic heart failure $[9,10]$. Given the increased risk for both all-cause and cardiovascular mortality (particularly sudden cardiac death) associated with poorly controlled resting heart rate, patient outcomes might improve if HR control was a core variable in patient management. Heart rate should be included in risk stratification of the ACS population as well as used as a tool to help guide clinical decisions regarding treatment options [11].

Although the 2010 ACC/AHA guidelines recommend a target resting HR of 50-60 bpm, these recommendations are mainly based on expert opinion with a clear lack of evidence from clinical trials ${ }^{3}$. Herman et al. showed that only $5.3 \%$ of the studied population achieved an average HR of 50-60 bpm throughout their hospital stay. Admission daily doses of Metoprolol averaged 58mg compared to discharge daily doses of $88 \mathrm{mg}$. Only $52 \%$ of patients had dosage increases prior to discharge. Irani et al. [12] demonstrated in a retrospective study of 516 patients that only $19 \%$ achieved a target HR of $60 \mathrm{bpm}$ even with the implementation of an institution wide protocol. Given the observation that titration of medication as an outpatient is often suboptimal, this highlights the importance to not only initiate but also optimize betablockade in the inpatient setting.

In a multi-center longitudinal observational study of 44708 patients from the REACH registry, Bangalore demonstrated that in those with recent MI (less than 1 year), beta-blocker use was associated with a lower incidence of the secondary outcome (OR, 0.77). However, betablockers were not associated with lower risk of cardiovascular events at the mean follow up of 44 months. An earlier meta-analysis also reported a reduction in death with beta-blocker therapy after MI, but the mean follow up in this study was only 1.4 years. No data has been reported on ACS patients correlating HR at time of discharge with incidence of major adverse cardiac events (MACE). Although there are ACC/AHA guidelines for resting HR (50-60 bpm), there is no specification on the time period in which this goal should be achieved in post myocardial infarction patients. There is also no recommendation for target HR at time of discharge.
As far as we are aware, to date no evidence-based clinical trials have investigated the optimal target heart rate in ACS patients with the initiation of beta-blockers or at the time of discharge. In previous studies recommendations for optimal degree of beta-blockade were determined by plasma drug concentration or by fixed dose of the betablocker. However, in these studies no association was seen between dose or plasma concentration and HR, demonstrating both to be poor objective measures of degree of beta-blockade. The aim of this study is to assess whether the survival benefit of beta-blockade in the ACS population has any correlation with baseline $\mathrm{HR}$, discharge $\mathrm{HR}$, or the degree of heart rate reduction.

\section{Patient Selection and Methods}

We performed a two-center retrospective chart review of all patients presenting with ACS to Providence Hospital and its satellite campus, Providence Park, from September 2006 to August 2011. Coronary angiography was performed at the Providence Heart Institute which is located within Providence Hospital and Medical Center, a 365-bed tertiary care facility located in Southfield, MI. Providence Park Hospital is a 260 bed facility located in Novi, MI.

All patients with diagnoses of either STEMI or NSTEMI who underwent coronary angiography with or without percutaneous coronary intervention (PCI) were screened from the Providence Heart Institute catheterization lab registry with IRB approval. Patients with STEMI that were either directly admitted to the hospital or transferred from the satellite campus for primary PCI were included. NSTEMI patients who experienced acute anginal type chest pain within 48 hours of admission, had positive biomarkers on two subsequent lab draws, and PCI within the first 48 hours of presentation were also included. Acknowledging that a variety of conditions including (but not limited to) renal failure, myocarditis, sepsis, tachyarrhythmias, acute pulmonary embolism and heart failure can also cause biomarker elevation, confirmation of ACS was based on anginal type pain with significant atherosclerosis of coronary arteries on heart catheterization. Patients who experienced unstable angina without elevation of biomarkers were not included in this study to eliminate provider bias in diagnosing UA. Patients who failed to survive to discharge as well as patients with contraindications to beta-blocker therapy (cardiogenic shock, significant bradycardia, systolic BP $<120 \mathrm{mmHg}$, decompensated heart failure, severe reactive airway disease and previous intolerance of beta-blockers) were also excluded.

Patient charts and procedure reports from cardiac catheterization were reviewed and patient information was obtained including age, gender, race, STEMI vs. NSTEMI, presenting HR (beats per minute) and BP (millimeters of mercury), discharge HR and BP, follow-up visit $\mathrm{HR}$ and $\mathrm{BP}$, medical history of hypertension, diabetes mellitus, tobacco use and dyslipidemia, length of hospital stay (in days), anti-platelet medications, ACE-inhibitors, Statins, and type and dose of beta-blocker at discharge. Ejection fraction was obtained via echocardiogram results done before the day of discharge. The average of three HR readings taken within 2-3 hours of admission and the average of three HR readings taken within 6-8 hours of discharge were calculated, using these values absolute change in HR from admission to discharge and percent change in HR from admission to discharge were also calculated. We initially tested then used analysis framework to compare admission $\mathrm{HR}$, discharge HR, absolute change between admission and discharge $\mathrm{HR}$ and percent difference between admission and discharge HR, and subsequently chose discharge $\mathrm{HR}$ as the predictor variable of interest based on statistical analysis. Equalization of beta-blocker type and dose 
to a Metoprolol equivalent was performed using an objective online calculator. (www.globalrph.com/beta_blockers.htm)

\section{Patient Follow-Up}

Patient follow-up data included the occurrence of STEMI, NSTEMI, unstable angina requiring hospitalization, exacerbation of congestive heart failure requiring hospitalization, stroke, cardiac arrest and all cause mortality (MACE). Hospital records, cardiac catheterization lab records, cardiology clinic and primary care physician clinic records were analyzed to obtain this follow up information. Patients with no follow up data from the previous sources were cross-referenced with the National Death Registry to confirm death (i.e. MACE), allowing for $100 \%$ yield on mortality follow-up. For patients not found in the National Death Registry, the absentee was interpreted as an indication that these patients had not experienced a major adverse cardiac event (MACE). This extrapolation may have resulted in some limitations, however these patients represent a very small portion $(<5 \%)$ of the total population studied. Outcome was analyzed at 1 month, 12 month, and 24 month end points. Lengths of hospital stay and individual outcome events were used as secondary end points.

\section{Analysis}

All statistical analyses were performed using SPSS version 15 Two-tailed statistical significance was set at a $\mathrm{p}$ value of 0.05 or less. Continuous variables were described using the mean and standard deviation. Categorical variables were described in counts and proportions as appropriate. The normal distribution was evaluated using the Shapiro-Wilk test. Continuous variables were compared using an appropriate Analysis Of Variance (ANOVA) test and in the case significant difference was found it was followed by pairwise testing of groups using the Student's t test or the non-paramentric MannWhitney $U$ test when the normal distribution could not be assumed. The Chi-square test was used to compare dichotomous variables. The hazard ratio was tested with student $t$ test.

\section{Results}

A total of 912 patients were included, 403 (44.2\%) presented with ST-segment elevation myocardial infarction (STEMI) and 509 (55.8\%) presented with non-ST-segment elevation myocardial infarction (NSTEMI). The total patient population was divided into five groups based on average discharge heart rate that led us into heart rate quintiles. Quintile 1 included all patients with heart rates less than $65 \mathrm{bpm}(\mathrm{n}=185)$, quintile 2 included HR of 65 to $70 \mathrm{bpm}(\mathrm{n}=187)$, quintile 3 included HR of 71 to $76 \mathrm{bpm}(\mathrm{n}=182)$, quintile 4 included HR of $77-83 \mathrm{bpm}(\mathrm{n}=182)$, and quintile 5 included heart rates greater than $83 \mathrm{bpm}(\mathrm{n}=176)$.

There was no statistically significant difference in baseline patient demographics (age, race, and gender) or risk factors (prevalence of hypertension, diabetes mellitus, tobacco use, and dyslipidemia) (Table 1). No significant difference was seen in TIMI risk index (calculated as (heart rate $\left.{ }^{\star}(\text { age/10 })^{\star} 2\right) /$ systolic blood pressure) on admission within the quintiles (Table 1). Median TIMI risk index for quintile 1 was 20 , quintile 2 was 23 , quintile 3 was 22 , quintile 4 was 23 , and quintile 5 was 22 . There was no significant difference in mean admission blood pressure among quintiles, with mean pressures being $144 / 80 \mathrm{mmHg}$, $141 / 79 \mathrm{mmHg}, 144 / 80 \mathrm{mmHg}, 141 / 83 \mathrm{mmHg}, 141 / 81 \mathrm{mmHg}$ in quintiles 1 through 5 respectively (Table 1). There was a statistically significant difference in the mean heart rate at the time of admission across quintiles, but there was no association with the composite endpoints when statistics performed on analytical framework (Data not shown).

There was no significant difference in mean BP at the time of discharge, with mean pressures of $121 / 66 \mathrm{mmHg}, 123 / 65 \mathrm{mmHg}$, $123 / 68 \mathrm{mmHg}, 125 / 71 \mathrm{mmHg}$, and $124 / 71 \mathrm{mmHg}$ in quintiles 1 through 5 respectively (Table 2 ). As there was a significant difference in Admission HR across Quintiles, we calculated the mean difference in admission HR and discharge HR in each Quintile. We found a statistically important trend across Quintiles. In Quintile 1, the mean difference was $+11.8+36$, in Quintile 2, the mean difference was +7.1 +37 , in Quintile 3, the mean difference was $+4.6+36$, in Quintile 4, the mean difference was $-1.25+50$ and in Quintile 5 , the mean difference was $-3.6+42$. This trend shows that as the Quintile increases, the degree of heart rate reduction was small and even in the negative trend in Quintile 4 and 5. We also knew from the preliminary analytical framework that Admission HR was not a predictor of outcome. Multiple beta blockers were used across quintiles. The most commonly used was Metoprolol and Carvedilol in $80 \%$ of patients. Other beta blockers included Labetalol, Atenolol, Bisoprolol and Nadolol. After approximate dose equivalence, the mean dose of beta-blocker at the

\begin{tabular}{|c|c|c|c|c|c|c|}
\hline Total patients $=912$ & $\begin{array}{l}\text { Quintile } 1 \text { RHR (48- } \\
\text { 64) } n=185\end{array}$ & $\begin{array}{l}\text { Quintile } 2 \text { RHR (65-70) } \\
\qquad n=187\end{array}$ & $\begin{array}{c}\text { Quintile } 3 \text { RHR (71-76) } \\
n=182\end{array}$ & $\begin{array}{l}\text { Quintile } 4 \text { RHR (77-83) } \\
n=182\end{array}$ & $\begin{array}{c}\text { Quintile } 5 \text { RHR (84- } \\
\text { 119) } n=176\end{array}$ & $\begin{array}{l}\text { p value } \\
\text { ANOVA }\end{array}$ \\
\hline Age (years) (Mean \pm S.D) & $61.4 \pm 13.6$ & $62.9 \pm 13.2$ & $61.9 \pm 12.6$ & $61.2 \pm 12.6$ & $60.4 \pm 14.2$ & $p=0.17$ \\
\hline Race (\% Caucasian) & $141(70.6 \%)$ & $135(72.1 \%)$ & $123(67.3 \%)$ & $133(73.0 \%)$ & $127(71.8 \%)$ & $p=0.85$ \\
\hline Gender (\% male) & $141(70.6 \%)$ & $135(72.1 \%)$ & $67.1 \%$ & $133(73.0 \%)$ & $127(71.8 \%)$ & $p=0.43$ \\
\hline HTN & $132(71.4 \%)$ & $135(72.4 \%)$ & $130(71.1 \%)$ & $133(73.1 \%)$ & $130(74.0 \%)$ & $p=0.76$ \\
\hline DM & $68(36.7 \%)$ & $67(36.0 \%)$ & $60(32.7 \%)$ & $61(33.0 \%)$ & $67(38.1 \%)$ & $p=0.07$ \\
\hline Smoking & $85(45.8 \%)$ & $76(40.5 \%)$ & $77(42.3 \%)$ & $82(45.0 \%)$ & $80(45.4 \%)$ & $p=0.92$ \\
\hline Dyslipidemia & $114(61.5 \%)$ & $105(55.9 \%)$ & $110(60.6 \%)$ & $93(51.0 \%)$ & $100(56.7 \%)$ & $p=0.35$ \\
\hline STEMI & $69(37.3 \%)$ & $85(45.4 \%)$ & $82(45 \%)$ & $82(45 \%)$ & $86(48.6 \%)$ & $p=0.1$ \\
\hline NSTEMI & $116(62.7 \%)$ & $102(54.7 \%)$ & $100(55 \%)$ & $100(55 \%)$ & $90(51.4 \%)$ & $p=0.1$ \\
\hline TIMI Risk Score & $19.6 \pm 9.8$ & $23.1 \pm 16.0$ & $22.3 \pm 10.6$ & $23.0 \pm 12.8$ & $22.2 \pm 2.5$ & $p=0.21$ \\
\hline Admission Mean SBP & $144.9 \pm 27.5$ & $141.8 \pm 29.2$ & $144.3 \pm 30.1$ & $141.4 \pm 30.7$ & $141.2 \pm 26.9$ & $p=0.83$ \\
\hline Admission Mean DBP & $80.3 \pm 17.0$ & $79.9 \pm 15.3$ & $80.8 \pm 17.7$ & $83.3 \pm 19.5$ & $81.8 \pm 20.3$ & $p=68$ \\
\hline Admission Mean HR & $70.8 \pm 14.7$ & $74.9 \pm 12.7$ & $78.3 \pm 14.1$ & $80.1 \pm 17.6$ & $87.9 \pm 18.1$ & $p=0.01$ \\
\hline
\end{tabular}

HTN - hypertension, DM - Diabetes Mellitus, Smoking - Patient who has smoked 1 pack per year for at least 10 years, Dyslipidemia - Patients who are documented as dyslipidemia and LDL at the time of admission is above 130, SBP - Systolic Blood Pressure, DBP - Diastolic Blood Pressure, HR - Heart Rate, STEMI - ST elevation myocardial Infarction, NSTEMI - Non ST elevation myocardial Infarction, TIMI risk index score at the time of admission $=($ heart rate* $($ age $/ 10)) /($ systolic blood pressure), predictor of long term mortality and heart failure in ACS patients. NS - Not significant

Table 1: Admission characteristics - Patient demographic factors, co-morbidities and vital signs by heart rate Quintile. (Mean \pm S.D) 
Citation: Jain SKA, Larsen TR, Wiemann C, Alexander P, Shaw M, et al. (2014) Degree of Beta-Blockade and Outcomes in Patients with Acute Coronary Syndrome. J Cardiovasc Dis Diagn 2: 150. doi:10.4172/2329-9517.1000150

Page 4 of 8

time of discharge was Metoprolol 25mg twice daily (total 50mg daily) across all quintiles (Table 2). There was no difference across quintiles as far as different types of beta blockers used.

There was a significant difference seen in mean ejection fraction (EF) at the time of discharge across quintiles (Table 2). We further divided patients in to two groups in each quintile with preserved $\mathrm{EF}$ and low EF $(<45 \%)$, we still found a significant difference across quintiles, with more patients with high EF in quintile 1 and less patients with low EF in quintile 5. Again on further analysis, though there was a difference in $\mathrm{EF}$ across quintiles, the range was from $43 \%$ to $50 \%$ with standard deviation of $10 \%$. This small difference in EF across quintiles (in mild impairment range) would not have influenced the heart rate at discharge. There was no significant difference in MACE related to degree of myocardial systolic dysfunction (Table 3).

The MACE rate for patients in quintile 1 was $9.1 \%$ compared to quintile 2 , which was $20.8 \%$, quintile 3 , which was $17.5 \%$, quintile 4 , which was $29.1 \%$, and quintile 5 , which was $21.6 \%$ a difference that is statistically significant (Figure 1). On further analysis, of the major adverse cardiac events that did occur in quintile 1 , the majority appeared to be more often associated with the lowest heart rates (below

\begin{tabular}{|c|c|c|c|c|c|c|}
\hline Total patients $=912$ & $\begin{array}{l}\text { Quintile } 1 \text { RHR (48- } \\
64) \text { n = } 185\end{array}$ & $\begin{array}{c}\text { Quintile } 2 \text { RHR (65- } \\
70) n=187\end{array}$ & $\begin{array}{c}\text { Quintile } 3 \text { RHR (71- } \\
76) n=182\end{array}$ & $\begin{array}{l}\text { Quintile } 4 \text { RHR (77- } \\
\text { 83) n = } 182\end{array}$ & $\begin{array}{l}\text { Quintile } 5 \text { RHR (84-119) } \\
n=176\end{array}$ & $\begin{array}{l}\text { p value } \\
\text { ANOVA }\end{array}$ \\
\hline Mean SBP & $121.5 \pm 12.5$ & $123.5 \pm 15.5$ & $123.3 \pm 18.1$ & $125.6 \pm 20.3$ & $123.8 \pm 21.3$ & $p=0.82$ \\
\hline Mean DBP & $68.7 \pm 10.9$ & $69.4 \pm 11.5$ & $68.5 \pm 11.6$ & $70.4 \pm 12.3$ & $70.9 \pm 15.6$ & $P=0.51$ \\
\hline Mean HR & $59.0 \pm 4.1$ & $67.8 \pm 1.9$ & $73.7 \pm 1.8$ & $79.8 \pm 1.9$ & $91.3 \pm 6.3$ & $p=0.01$ \\
\hline $\begin{array}{l}\text { Mean Difference in } \\
\text { Admission HR and } \\
\text { Discharge HR }\end{array}$ & $+11.8 \pm 36$ & $+7.1 \pm 37$ & $+4.6 \pm 36$ & $-1.25 \pm 50$ & $-3.6 \pm 42$ & $p=0.01$ \\
\hline Mean Ejection Fraction & $50.4 \pm 10.1$ & $48.6 \pm 10.4$ & $49.9 \pm 10.7$ & $46.1 \pm 11.5$ & $43.6 \pm 12.6$ & $p=0.01$ \\
\hline $\begin{array}{l}\text { Total number of patients with } \\
\text { EF >= } 45 \%\end{array}$ & $119(64.3 \%)$ & $106(56.7 \%)$ & $107(58.7 \%)$ & $88(48.3 \%)$ & $67(38.0 \%)$ & $p=0.01$ \\
\hline $\begin{array}{l}\text { Total number of patients with } \\
\text { EF }<45 \%\end{array}$ & $66(35.7 \%)$ & $81(43.3 \%)$ & $75(41.3 \%)$ & $94(51.7 \%)$ & $109(62 \%)$ & $p=0.01$ \\
\hline $\begin{array}{l}\text { Beta blocker approximate } \\
\text { dose equivalence (Metoprolol } \\
\text { - total dose in mg twice } \\
\text { daily) }\end{array}$ & $25 \mathrm{mg}$ & $25 \mathrm{mg}$ & $25 \mathrm{mg}$ & $25 \mathrm{mg}$ & $25 \mathrm{mg}$ & $p=0.1$ \\
\hline
\end{tabular}

SBP - Systolic Blood Pressure, DBP - Diastolic Blood Pressure, HR - Heart Rate, EF (\%) - Ejection Fraction in percentage

Table 2: Discharge characteristics - Patient vital signs by heart rate Quintile (Mean \pm S.D).

\begin{tabular}{|c|c|c|c|c|c|}
\hline Total patients $=912$ & $\begin{array}{l}\text { Quintile } 1 \text { RHR (48-64) } \\
\qquad n=185\end{array}$ & $\begin{array}{l}\text { Quintile } 2 \text { RHR (65-70) } \\
\qquad n=187\end{array}$ & $\begin{array}{l}\text { Quintile } 3 \text { RHR (71-76) } \\
\qquad n=182\end{array}$ & $\begin{array}{l}\text { Quintile } 4 \text { RHR (77-83) } \\
\qquad n=182\end{array}$ & $\begin{array}{l}\text { Quintile } 5 \text { RHR (84-119) } \\
n=176\end{array}$ \\
\hline MACE in EF > $=45 \%$ & $11 / 119(9.2 \%)$ & $21 / 106(20.2 \%)$ & $18 / 107(16.8 \%)$ & $23 / 88(26.1 \%)$ & $11 / 67(16.4 \%)$ \\
\hline MACE in EF <45\% & $6 / 66(9.1 \%)$ & $13 / 81(22.2 \%)$ & $14 / 75(18.7 \%)$ & $30 / 94(31.9 \%)$ & $27 / 109(24.7 \%)$ \\
\hline$P$ value ANOVA & $p=0.99$ & $p=0.80$ & $p=0.73$ & $p=0.14$ & $p=0.25$ \\
\hline
\end{tabular}

EF (\%) - Ejection fraction in percentage, MACE - Major Adverse Cardiac Events

Table 3: Distribution of Major Adverse Cardiac Events (MACE) across all quintiles by the presence of systolic dysfunction.

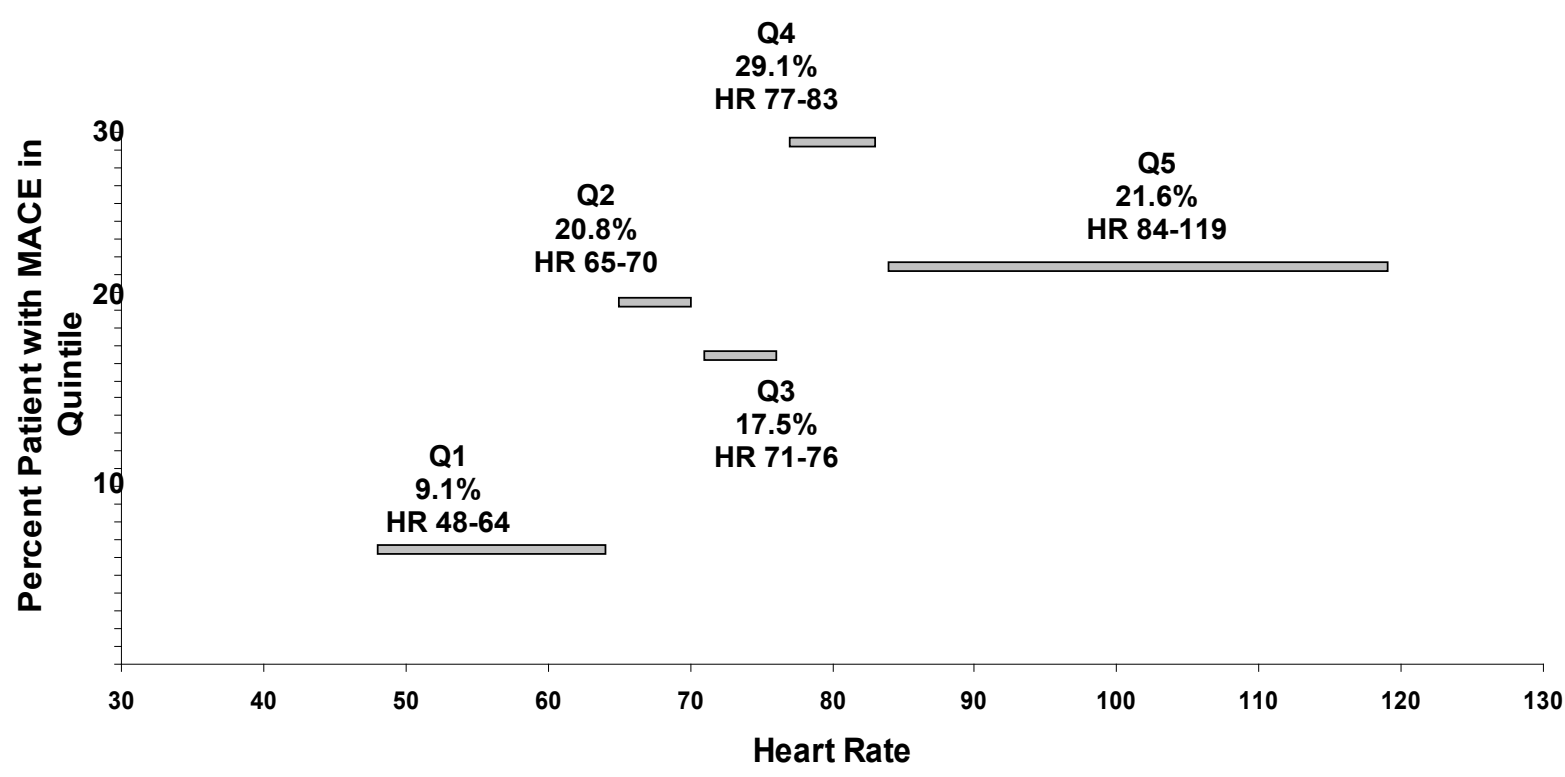

Figure 1: Distribution of Major Adverse Cardiac Events (MACE) across heart rate quintiles. 
Citation: Jain SKA, Larsen TR, Wiemann C, Alexander P, Shaw M, et al. (2014) Degree of Beta-Blockade and Outcomes in Patients with Acute Coronary Syndrome. J Cardiovasc Dis Diagn 2: 150. doi:10.4172/2329-9517.1000150

Page 5 of 8

$55 \mathrm{bpm})$. The relative hazard ratio of Major Adverse Cardiac Events (MACE) of being in Quintile 2 through 5 compared to Quintile 1 is shown in Figure 2.

On secondary analysis of MACE there was a significant difference in occurrence of acute coronary events lower in quintile 1 compared to higher in other quintiles (Table 4). There were no differences found across quintiles in terms of other adverse events including exacerbation of congestive heart failure requiring hospitalization, cardiac arrest, stroke and all cause mortality at the 24-month follow-up. Length of hospital stay (in days) was also similar across all quintiles with 2.8 days for quintile $1,3.1$ for quintile 2, 3.4 for quintile $3,3.0$ for quintile 4 , and 3.2 for quintile 5 .

\section{Discussion}

In the modern era of reperfusion therapy, the analysis we conducted determined that primary outcome (major adverse cardiac events) was in fact predicted by resting heart rate at the time of discharge. The quintile with the lowest resting heart rate $(<65 \mathrm{bpm})$ had a significantly lower rate of MACE at $9.1 \%$ compared to $20.8 \%, 17.5 \%, 29.1 \%$, and $21.6 \%$ in quintiles 2 through 5 respectively, and within that quintile the lowest mortality was seen with heart rates between 55-65. Thus our study supports treating resting heart rate by optimizing the degree of beta-blockade (goal 55-65 bpm) individually for each patient at the time of discharge. Also from Table 2, we saw that as the Quintile increases, the degree of heart rate reduction was small and even in the negative trend in Quintile 4 and 5, acknowledges the fact that higher beta blocker dosage should have been used in higher Quintiles to decrease the HR for better control.

Pharmacologic blockade of the beta adrenergic system after an acute myocardial infarction (AMI) has been shown to improve survival. In the current ACC/AHA guidelines (updated in 2011) oral beta blocking agents are given a class I recommendation in appropriate patients [13]. The benefits of beta blockade include (but are not limited to) decreased myocardial oxygen demand, suppression of arrhythmias, improved coronary artery blood flow, decrease ventricular remodeling, and slowed progression of atherosclerotic disease [14]. In a large metaanalysis including 25,000 patients, Freemantle et al. [15] identified a $10.1 \%$ reduction in overall mortality in patients treated with betablockers versus placebo. Thus beta-blockers represent a mainstay in therapy for secondary prevention following an AMI.

Despite the widespread use of beta-blockers following AMI data regarding optimal dosage is limited. The ACC guidelines recommend titrating beta blockers to a dose sufficient to induce a resting heart rate of 50 to 60 beats per minute. This recommendation is based on expert opinion with the majority of data available on the subject collected from trials conducted several decades ago in the thrombolytic era of treatment. In a large meta-regression analysis Cucherat identified a statistically significant relationship between heart rate and log odds

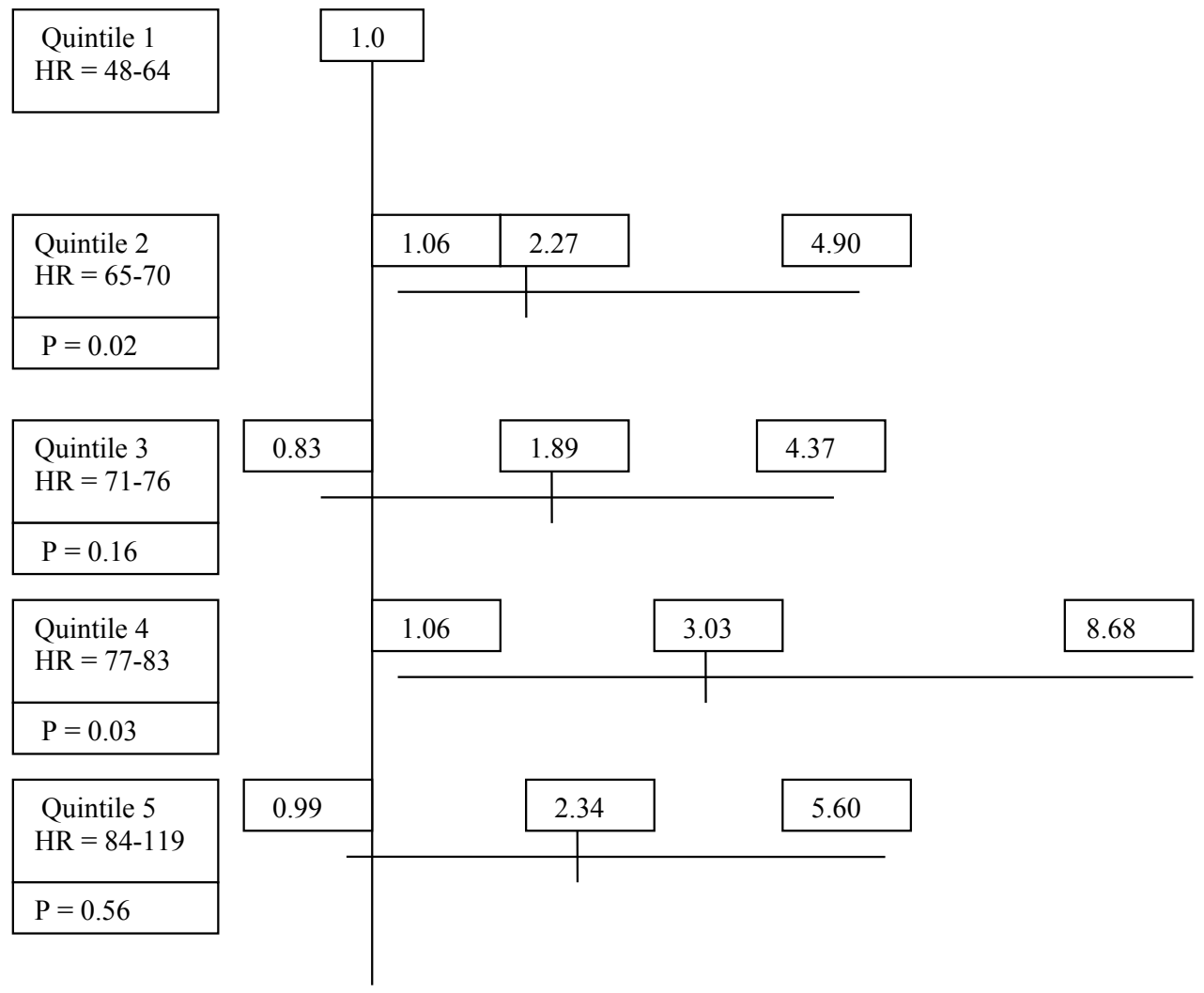

Figure 2: Relative hazard ratio of Major Adverse Cardiac Events (MACE) of being in Quintile 2 through 5 compared to Quintile 1). 


\begin{tabular}{|c|c|c|c|c|c|c|}
\hline Total patients $=912$ & $\begin{array}{c}\text { Quintile } 1 \text { RHR (48- } \\
64) \mathrm{n}=185\end{array}$ & $\begin{array}{l}\text { Quintile } 2 \text { RHR (65-70) } \\
n=187\end{array}$ & $\begin{array}{c}\text { Quintile } 3 \text { RHR (71-76) } \\
n=182\end{array}$ & $\begin{array}{l}\text { Quintile } 4 \text { RHR (77-83) } \\
\qquad n=182\end{array}$ & $\begin{array}{c}\text { Quintile } 5 \text { RHR (84- } \\
\text { 119) } n=176\end{array}$ & $\begin{array}{c}\text { p value ANOVA } / \\
\text { Chi2 }\end{array}$ \\
\hline MACE & $17(9.1 \%)$ & $39(20.8 \%)$ & $32(17.5 \%)$ & $53(29.1 \%)$ & $38(21.6 \%)$ & 0.002 \\
\hline ACS & $10(5.3 \%)$ & $25(13.3 \%)$ & $18(9.8 \%)$ & $34(18.7 \%)$ & $25(14.2 \%)$ & 0.01 \\
\hline STEMI & 1 & 1 & 2 & 3 & 3 & 0.1 \\
\hline Non STEMI & 7 & 20 & 12 & 25 & 17 & 0.04 \\
\hline Unstable angina & 2 & 4 & 4 & 6 & 5 & 0.1 \\
\hline CHF & $4(2.2 \%)$ & $8(4.3 \%)$ & $8(4.4 \%)$ & $9(5.0 \%)$ & $7(4.0 \%)$ & 0.73 \\
\hline Cardiac arrest & $1(0.5 \%)$ & $2(1.0 \%)$ & $2(1.1 \%)$ & $4(2.2 \%)$ & $3(1.7 \%)$ & 0.69 \\
\hline Stroke & $0(0 \%)$ & $1(0.6 \%)$ & $0(0 \%)$ & $1(0.5 \%)$ & $0(0 \%)$ & 0.57 \\
\hline All cause Mortality & $2(1.1 \%)$ & $3(1.6 \%)$ & $4(2.2 \%)$ & $5(2.7 \%)$ & $3(1.7 \%)$ & 0.81 \\
\hline $\begin{array}{l}\text { Median length of Stay } \\
\text { (days) }\end{array}$ & $2.6 \pm 1.6$ & $3.1 \pm 2.5$ & $3.5 \pm 3.8$ & $3.0 \pm 2.4$ & $3.2 \pm 2.5$ & 0.24 \\
\hline
\end{tabular}

MACE - Major Adverse Cardiac Events (ST Elevation Myocardial Infarction, Non ST Elevation Myocardial Infarction, unstable angina requiring hospitalization, congestive heart failure requiring hospitalization, stroke, cardiac arrest and all cause mortality), ACS - Acute Coronary Syndromes (ST Elevation Myocardial Infarction, Non ST Elevation Myocardial Infarction, unstable angina requiring hospitalization), CHF - congestive heart failure requiring hospitalization, STEMI - ST elevation myocardial Infarction, NSTEMI - Non ST elevation myocardial Infarction.

Table 4: MACE events, all cause mortality at two years and hospital length of stay by heart rate quintile.

ratio for cardiac death $(\mathrm{P}=0.02)$, sudden death $(\mathrm{P}<0.01)$, and nonfatal myocardial infarction $(\mathrm{P}<0.01)$. The randomized clinical trials included in this analysis, however, were conducted in the 1970s and 1980s when the primary treatment modality for AMI was medical management.

The most recent clinical trials evaluating the effectiveness of betablockers after AMI used relatively high doses as the goal (equivalent of Metoprolol $200 \mathrm{mg}$ daily). This may be difficult to achieve in routine clinical practice largely secondary to patient intolerance of side effects associated with larger doses. Ideally medications should be titrated to achieve the desired clinical result at the lowest effective dose in order to minimize side effects. Titration of beta-blockers to treat angina, arrhythmias, and hypertension has demonstrated that the effective dose varies widely from patient to patient. When used for secondary prevention, such as in ACS, it is more difficult to identify the appropriate dose for desired clinical effect. Prior studies have used exercise heart rate and plasma concentrations, both of which require complex additional testing with concomitant increased cost and turnaround time [16]. Our results suggest that resting heart rate at discharge may be a reliable, noninvasive, inexpensive and simple method to determine if treatment goal has been met when titrating beta-blocker dose.

Several studies have demonstrated the inconsistency of patient response to beta-blocker therapy. Wikstand et al. [17] showed that after three months patients taking low dose metoprolol $(<100 \mathrm{mg})$ achieved a similar mean HR as patients taking high dose $(>100 \mathrm{mg})$. Similar risk reduction in both groups was also seen, indicating that optimal degree of beta blockade is not achieved with the same dose in every patient. Genetic variability in the expression of beta-receptors can exist in the form of single nucleotide polymorphisms (SNP), some of which have clinical significance. Age and the presence of CHF are also associated with variability in expression and function of beta-receptors. A recent article reviewed several studies that investigated the pharmacogenetics of beta-blockers and clinical response in individual patients. Multiple endpoints were examined and correlated to different genetic and physiologic factors that play a role in the variability of patient response. This further supports the suggestion that targeting HR as a treatment goal, rather than beta-blocker dose or type would ensure that patients were more consistently achieving optimal degree of beta-blockade and therefore optimal benefit.

With all patients considered, MACE rate plotted against discharge resting heart rate produced a J-shaped curve (Figure 3). The rate of MACE appears to increase as the heart rate is lowered below 55 beats per minute. These findings suggest there is an ideal resting heart rate between 55 and 65 beats per minute in patients discharged after myocardial infarction. Cullington et al. [18] demonstrated similar findings in patients receiving beta-blocker therapy for chronic heart failure. They found a mortality benefit for patients with resting heart rates between 58 and $64 \mathrm{bpm}$, mortality rates increased with heart rates $<58$ or $>74$ bpm [19-21]. In another study analyzing the HF-ACTION trial population an inverse relationship was seen between beta-blocker dose and the outcome of all cause death or all cause hospitalization. A linear relationship was demonstrated with increasing daily dose of Carvedilol up to $50 \mathrm{mg} /$ day and decreasing all cause death and hospitalization rates, however, when doses were increased above $50 \mathrm{mg}$ the rate of all cause death and hospitalization began to increase. This study also showed the lowest cardiovascular adverse event rates occurred in the 26-50 mg daily dose group, which further supports our conclusions that achieving optimal degree beta-blockade (based on HR response) is more beneficial than reaching a maximum dose.

As previously mentioned, the mortality benefit of beta-blockers is greatest within the first year of therapy in the ACS population as well as the heart failure population. Considering this with the observation of poor titration of beta-blocker dose including suboptimal HR control in the outpatient setting, this should be addressed more aggressively in the inpatient setting. We believe it is imperative to not only initiate but also appropriately titrate beta-blockade at discharge to achieve the greatest patient benefit.

\section{Study Limitations}

Due to the retrospective nature of our analysis, any residual unmeasured confounding factors such as physician treatment preferences, drug tolerability, sympathetic nervous system influence etc., cannot be excluded. However, any prospective study would be extremely difficult to perform today due to limitations that established post-MI standards of care would place on the researcher (i.e. US standards of care make it unethical to treat post-MI patients with placebo $\mathrm{BB}$ ). In addition, we were unable to obtain data on beta blocker use prior to the studied admission as records. Although type of beta-blocker and dose at discharge were recorded, change in dose or brand from discharge to first outpatient was not. Information regarding individual patient medication regime (pre and post analysis) was unable to be obtained secondary to the inaccuracy of patient recall and the large number of private pharmacies in the U.S.A. The general trend in initiation of beta-blocker therapy is to begin with a low dose 
Citation: Jain SKA, Larsen TR, Wiemann C, Alexander P, Shaw M, et al. (2014) Degree of Beta-Blockade and Outcomes in Patients with Acute Coronary Syndrome. J Cardiovasc Dis Diagn 2: 150. doi:10.4172/2329-9517.1000150

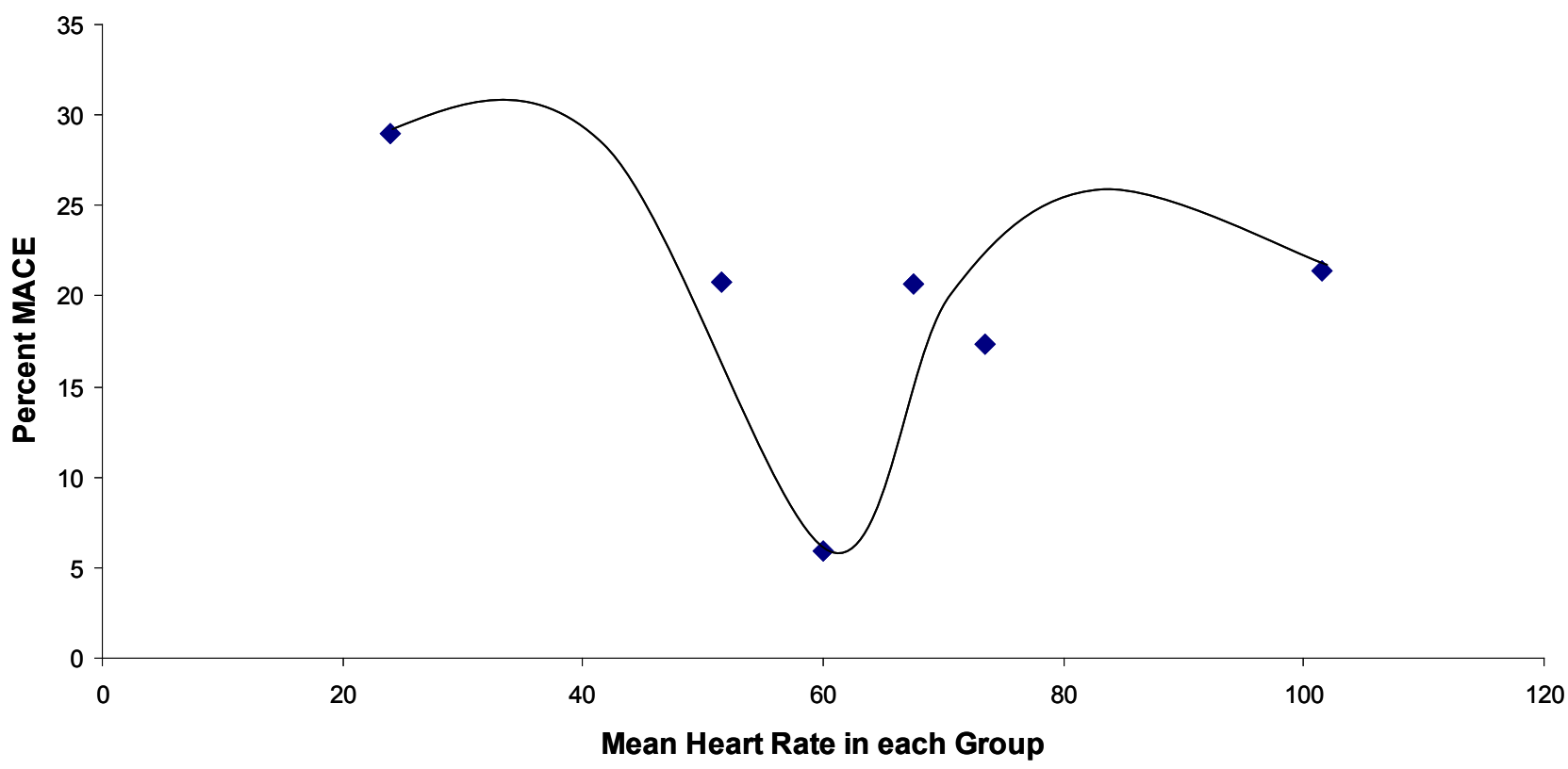

Figure 3: Major Adverse Cardiac Events (MACE) plotted against resting heart rate at discharge produces a J-shaped curve.

and increase as tolerated by the patient. Some physicians may use other strategies such as starting with a maximum dose and titrating down based on patient tolerated side effects. Patients previously established on beta-blocker therapy pre-event (ACS) may have been re-started on a higher dose post-event based on physician preference. This lack of information on method of original beta-blocker prescription (preevent) and lack of follow-up dosing could potentially mask differences in patient response to therapy.

\section{Conclusion}

Resting heart rate at discharge in patients treated with betablocking therapy after ACS is an important determinant of patient outcome. High resting heart rate at discharge is a predictor for major adverse cardiac events independent of other risk factors in patients with ACS. In those with ACS, particularly STEMI and NSTEMI, a lower discharge HR conferred a decreased composite endpoint at 24 months with the best outcomes seen at a resting heart rate between 55 and 65 . It's unclear whether the long-term benefit with this degree of HR reduction at discharge will persist. Further studies are needed to confirm the clinical benefit of HR reduction in the ACS population beyond 24 months.

\section{Acknowledgements}

We thank Drs Anjali Modi, MD and Yousif Ismail, MD at Providence Hospitals and Medical Centers for their kindness to co-ordinate and assist with data collection.

\section{References}

1. Agostini-Miranda A, Crown LA (2009) An Approach to the Initial Care of Patients with Chest Pain in an Emergency Department Located in a NonCardiac Center. American Journal of Clinical Medicine Winter 6: 24.

2. Zhao Z, Winget M (2011) Economic burden of illness of acute coronary syndromes: medical and productivity costs. BMC Health Serv Res 11: 35.

3. Wright RS, Anderson JL, Adams CD, Bridges CR, Casey DE Jr, et al. (2011) 2011 ACCF/AHA focused update of the Guidelines for the Management of Patients with Unstable Angina/Non-ST-Elevation Myocardial Infarction (updating the 2007 guideline): a report of the American College of Cardiology Foundation/American Heart Association Task Force on Practice Guidelines developed in collaboration with the American College of Emergency Physicians, Society for Cardiovascular Angiography and Interventions, and Society of Thoracic Surgeons. J Am CollCardiol 57: 1920-1959.

4. Yusuf S, Peto R, Lewis J, Collins R, Sleight $P$ (1985) Beta blockade during and after myocardial infarction: an overview of the randomized trials. ProgCardiovasc Dis 27: 335-371.

5. Herman M, Donovan J, Tran M, McKenna B, Gore JM, et al. (2009) Use of beta-blockers and effects on heart rate and blood pressure post-acute coronary syndromes: are we on target? Am Heart J 158: 378-385.

6. Rengo G, Lymperopoulos A, Zincarelli, Femminella GD, Liccardo D, et al. (2012) Blockade of Beta-adenoceptors restores the GRK2-mediated adrenal alpha2-adrenoceptor-catecholamine production axis in heart failure. $\mathrm{Br} \mathrm{J}$ Pharmacol 166: 2430.

7. Palatini $P(2005)$ Heart rate: a strong predictor of mortality in subjects with coronary artery disease. Eur Heart J 26: 943-945.

8. Cucherat M (2007) Quantitative relationship between resting heart rate reduction and magnitude of clinical benefits in post-myocardial infarction: a meta-regression of randomized clinical trials. Eur Heart J 28: 3012-3019.

9. Palatini P, Thijs L, Staessen JA, Fagard RH, Bulpitt CJ, et al. (2002) Predictive value of clinic and ambulatory heart rate for mortality in elderly subjects with systolic hypertension. Arch Intern Med 162: 2313-2321.

10. McAlister FA, Wiebe N, Ezekowitz JA, Leung AA, Armstrong PW (2009) Metaanalysis: beta-blocker dose, heart rate reduction, and death in patients with heart failure. Ann Intern Med 150: 784-794.

11. Feldman D, Elton TS, Menachemi DM, Wexler RK (2010) Heart rate contro with adrenergic blockade: clinical outcomes in cardiovascular medicine. Vasc Health Risk Manag 6: 387-397.

12. Irani F, Herial N, Colyer WR Jr (2012) Impact of an acute coronary syndrome pathway in achieving target heart rate and utilization of evidence-based doses of beta-blockers. Am J Ther 19: 397-402.

13. Smith SC Jr, Benjamin EJ, Bonow RO, Braun LT, Creager MA, et al. (2011) AHA/ACCF Secondary Prevention and Risk Reduction Therapy for Patients with Coronary and other Atherosclerotic Vascular Disease: 2011 update: a guideline from the American Heart Association and American College of Cardiology Foundation. Circulation 124: 2458-2473.

14. López-Sendón J, Swedberg K, McMurray J, Tamargo J, Maggioni AP, et al (2004) Expert consensus document on beta-adrenergic receptor blockers. Eur Heart J 25: 1341-1362. 
Citation: Jain SKA, Larsen TR, Wiemann C, Alexander P, Shaw M, et al. (2014) Degree of Beta-Blockade and Outcomes in Patients with Acute Coronary Syndrome. J Cardiovasc Dis Diagn 2: 150. doi:10.4172/2329-9517.1000150

Page 8 of 8

15. Freemantle N, Cleland J, Young P, Mason J, Harrison J (1999) beta Blockade after myocardial infarction: systematic review and meta regression analysis. BMJ 318: 1730-1737.

16. Sklar J, Johnston GD, Overlie P, Gerber JG, Brammell HL, et al. (1982) The effects of a cardioselective (metoprolol) and a nonselective (propranolol) beta-adrenergic blocker on the response to dynamic exercise in normal men. Circulation 65: 894-899.

17. Wikstrand J, Hjalmarson A, Waagstein F, Fagerberg B, Goldstein S, Kjekshus J, Wedel H (2002). Dose of Metoprolol CR/XL and Clinical Outcomes in Patients With Heart Failure: Analysis of the Experience in Metoprolol CR/SL Randomized Intervention Trial in Chronic Heart Failure (MERIT-HF). J Am CollCardiol 40: 491.

18. Cullington D, Goode KM, Clark AL, Cleland JG (2012) Heart rate achieved or beta-blocker dose in patients with chronic heart failure: which is the better target? Eur J Heart Fail 14: 737-747.

19. [No authors listed] (1982) A randomized trial of propranolol in patients with acute myocardial infarction. I. Mortality results. JAMA 247: 1707-1714.

20. Fiuzat M, Wojdyla D, Kitzman D, Fleg J, Keteyian SJ, et al. (2012) Relationship of beta-blocker dose with outcomes in ambulatory heart failure patients with systolic dysfunction: results from the HF-ACTION (Heart Failure: A Controlled Trial Investigating Outcomes of Exercise Training) trial. J Am CollCardiol 60: 208-215.

21. von Homeyer $P$, Schwinn DA (2011) Pharmacogenomics of $\hat{i}^{2}$-adrenergic receptor physiology and response to ${ }^{2}$-blockade. AnesthAnalg 113: 1305-1318. 